connections form that allow you to crawl, walk and then talk. There is then a process of constant organization and reorganization that continues until early adult life and beyond. This process, known as brain plasticity, is the basis for Andreasen's self-help guide to improved creativity. She advises us to perform mental exercises, explore unfamiliar fields of endeavour, meditate or " ${ }^{\alpha u s t}$ think", practise observing, describing and imagining. And kids must turn off the TV, read, explore the natural world and listen to dassical music. Despite what might seem like reasonable offerings, this section, and maybe others too, could perhaps have been complemented by a reference list to allow some assessment of the arguments and suggestions presented.

Andreasen writes with clarity and ease, interspersing personal and scientific opinion. She makes wonderful connections between the arts and sciences, which surely spring from her background in literature. And she provides a succinct overview of diverse fields of investigation, as well as providing a perspective that reaches beyond the usual approaches to understanding the relationship between creativity and the brain.

Mark Lythgoe is a neurophysiologist in the Radiology and Physics Unit, Institute of Child Health, 30 Guilford Street, London WC1N1EH, UK.

\title{
Digging for clues
}

\section{Discovering Dor othea: The Life of the \\ Pioneering Fossil-Hunter Dorothea Bate by Karolyn Shindler \\ HarperCollins: 2005. 304 pp. $€ 25$}

\section{Jennifer Clack}

The slightly blurred, somewhat ghostly figure caught in a pose of resolute determination on the cover of this book is a highly appropriate image and captures the essence of the subject. How do you write a biography of someone who left virtually no personal documents, but a wealth of published scientific articles? The author, Karolyn Shindler, faced this problem when she tackled the life of Dorothea Bate, a pioneering female palaeontologist who worked in the first half of the twentieth century.

Bate's interest in natural history and fossils began early, when she was about ten. It seems to have arisen spontaneously, rather than from the influence of any adult around her - this is often the way with palaeontologists and natural historians. The absence of any personal diaries, from any stage of her life, leaves unanswered questions, such as what motivated her initially, and what drove her to continue against a multitude of difficulties. Her initiative in beginning such daunting adventures as expeditions to remote and poorly resourced locations with only sporadic, sometimes unreliable, local support was exceptional, and leaves me feeling inadequate. What's more, it is clear that she had to face parental opposition and relative poverty from time to time. On the other hand, she received appreciative support from professional palaeontologists at the British Museum (Natural History) in London - male, of course - who recognized her unique contributions. If I have a criticism of Shindler's writing, it is that, in the early parts of the story, the difficulties are somewhat overemphasized to become almost tedious, whereas the successes are downplayed.

She was remarkable for more than being a female palaeontologist at a time when the discipline, and its locations, were male dominated. She also pioneered collecting from previously unexplored and almost inaccessible parts of several Mediterranean islands, discovering new species and faunas from the Pleistocene of the area, and demonstrating

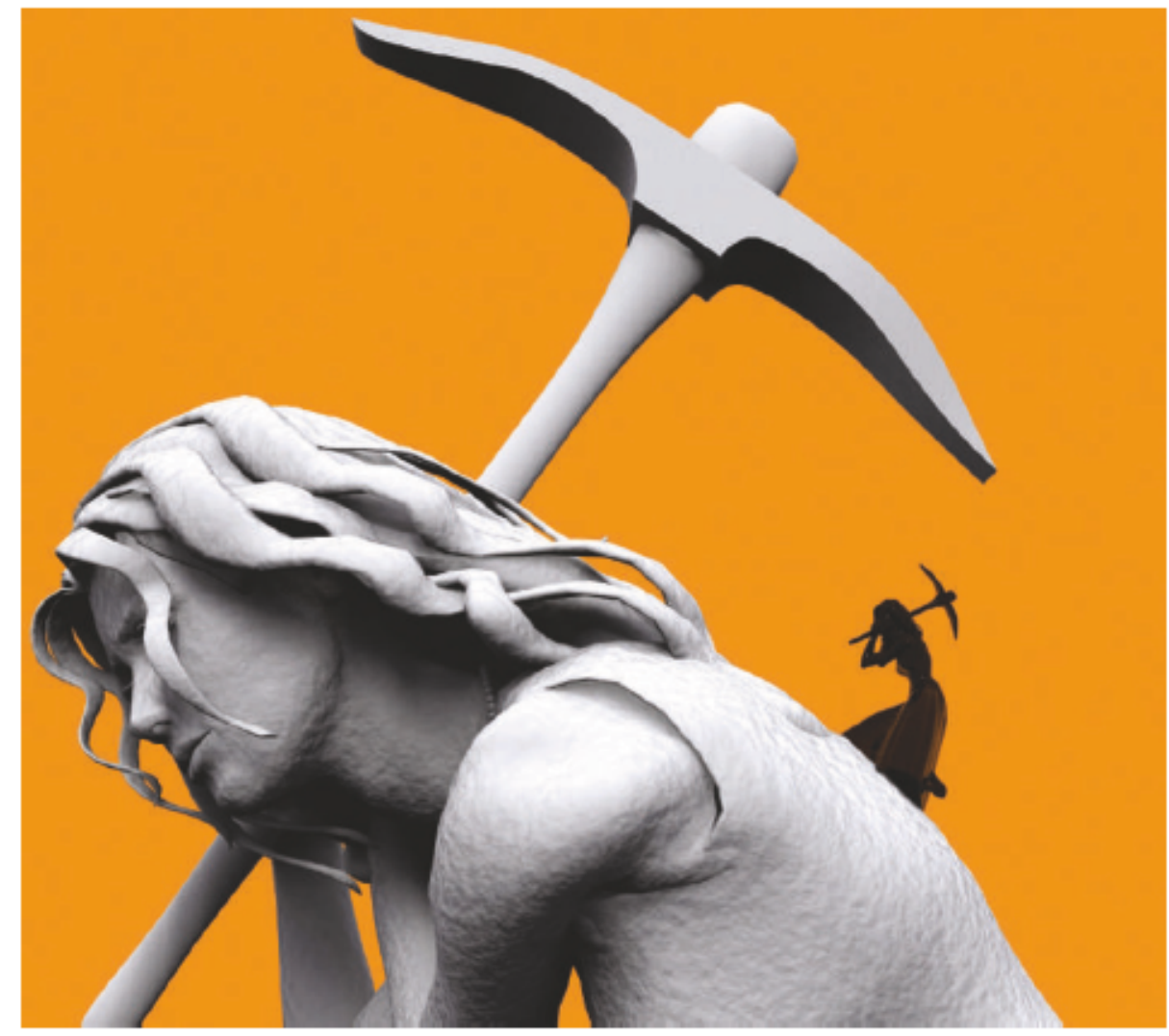

the idea, novel at the time, that island dwarfing of elephants and hippos occurred in parallel on several islands.

As Bate grew in experience and academic stature, she began to integrate evidence from many sites and faunas to infer dimatic changes over recent millennia, at a time when such thinking was in its infancy. She later incorporated this evidence with new finds in archaeology and anthropology to place human remains in their faunal context. She was among the first to recognize that the animals associated with ancient human habitations could shed considerable light on human activities and ecology, and she brought ideas of climate change to bear on human evolution through the Pleistocene. I was previously unaware of her work (my work deals with Palaeozoic fossils), but my colleagues who work on Pleistocene or Quaternary material not only know of her but continue to use the material she collected. Her ideas and techniques were ahead of her time. Her extensive publication record began in 1901 and continued to grow in depth and understanding, and with undiminished energy, until 1955. Despite this, it was not until near the end of her life that she gained permanent paid full-time employment, at the British Museum (Natural History)'s site in Tring.

In her later endeavours, she developed friends and colleagues in the archaeological world, several of whom were also women, and some went on to be pioneers in other respects. Dorothy Garrod, for example, was the first woman professor at the University of Cambridge. It is as though archaeology was already seen as a field in which women could play a significant role.

This biography could perhaps be criticized for its lack of in-depth analysis of the subject's personality or psyche, or that bringing to 
attention a 'forgotten woman in a man's world' is passé in the early twenty-first century. However, I think the author is justified on other grounds. With almost all of Bate's personal records, such as diaries or photographs, having been lost, destroyed or perhaps never made, Shindler has focused instead on the work of a scientist of considerable ability, originality and resourcefulness. Perhaps it is today's almost voyeuristic obsession with the analysis of motives and feelings, and the cult of personality, that leads us to expect a biography to address such issues - especially as the subject is female, and therefore 'ought' to have recorded her innermost feelings. I certainly don't keep any such diaries, and I wonder how many of my fellow scientists do.

In this biography, then, we are dealing first and foremost with a scientific record. In the end, it is the results of her research - the new specimens, species and their descriptions that stand the test of time. I am grateful to Shindler for bringing Bate and her work to my attention.

Jennifer Clack is at the University Museum of

Zoology, Downing Street, Cambridge CB2 3EJ, UK.

\section{A Stone Age greenhouse}

Plows, Plagues and Petroleum: How

Humans Took Control of Climate

by William F. Ruddiman

Princeton University Press: 2005. 272 pp.

$\$ 24.95, £ 15.95$

\section{Robert J.Charlson}

The activities of Stone Age farmers may have altered Earth's climate. This is the exciting but controversial theory conveyed by palaeoclimatologist William Ruddiman in his wellwritten book Plows, Plagues and Petroleum.

I am not a climatologist, but my work on atmospheric chemistry, aerosols and cloud physics relates to Ruddiman's analysis of Earth's climate over the past few millennia. Aerosols and clouds must be included in any analysis of palaeodimate because they are so variable and exert such a powerful influence on the albedo of the planet. It cannot be assumed that they remained constant over this time. I strongly support Ruddiman's view that fitting all these pieces together to figure out the key cause-and-effect relationships "makes studying climate history fun".

Ruddiman's book is unusual because he candidly describes his main ideas as a thesis rather than as fact, and states that they are currently being debated in refereed publications. This high level of candour will certainly be appreciated by scientists, and the book's descriptive analogies and lack of jargon make it accessible to the lay reader as well.

The book starts with the importance of climate to human history, the basic science of climate, the connections between Earth's orbit and climate, and the modulation of ice ages, monsoon circulations and climate, with "nature in control".

The main thesis then emerges, with a description of the inexorable changes imposed by humans on the chemical composition of Earth's atmosphere. Starting with Ruddiman's strongest scientific argument, the increase of the greenhouse gas methane about 5,000 years ago is attributed to Stone Age farming. Simple calculations of the amount of methane generated per person by flood irrigation, animal

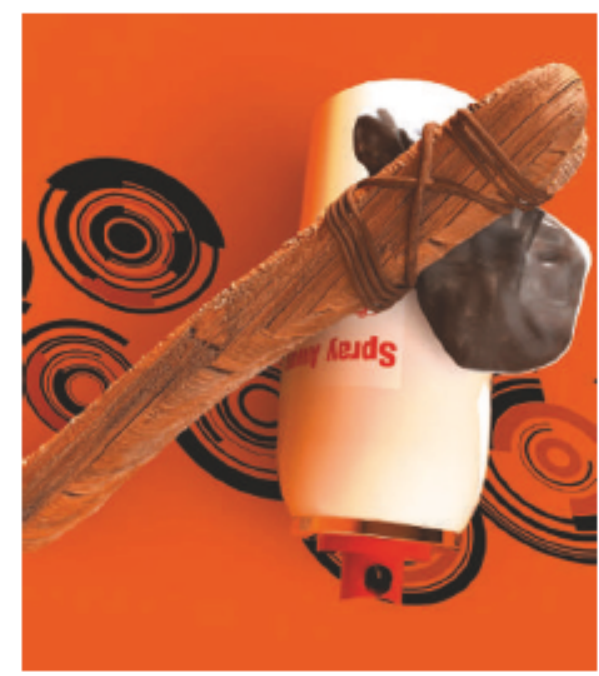

husbandry and biomass burning show emission rates high enough to explain the methane data obtained from ice cores.

Other population-based estimates for the emission of carbon dioxide, another greenhouse gas, show that over a period of several thousand years, enough biomass combustion could have occurred during land clearing to increase the concentration by the observed amount, 40 parts per million. Stone Age humans apparently began burning forests about 8,000 years ago, which fits with the time series of carbon dioxide data.

Moving from the data-based analysis of rising levels of methane and carbon dioxide to the tentative business of climate forecasting, Ruddiman then asks: ${ }^{\alpha}$ Have we delayed a glaciation?" He thinks we have, arguing that the stability of the climate over the past 10,000 years " may have been an accident". The warmth of the past several thousand years "stems from a colossal coincidence: a natural cooling" that was "offset by a human-induced warming".

Then, in what almost seems to be an afterthought, the small 'wiggles' in the carbon dioxide record and a decrease in the rate of its increase over the past 2,000 years are interpreted to have been caused by the decimation of human populations in epidemics and pandemics. Smaller populations produced less carbon dioxide, adding yet more variables to the study of palaeodimate.

The main part of the book concludes with three chapters on the nature of climate in a future with "humans in control". Ruddiman provides a vivid description of the immensity of human influence on the climate and on the environment in general. The growth of greenhouse gases is singled out, with carbon dioxide and methane being dominant. The paradoxically small observed temperature increase in the industrial period (about $0.6^{\circ} \mathrm{C}$ ), compared with the larger rise of $0.8^{\circ} \mathrm{C}$ caused by previous human activity, is attributed to a delay in climate response and to cooling factors generated by humans, such as sulphate aerosols.

Current global warming is then analysed over a shorter time scale (centuries) by means of uncertain estimates of the future rate of carbon dioxide and methane emission by human activities. This shorter-term analysis is then set in the context of the distant past (with nature in control) and for several centuries in the future (under human influence), all properly labelled as uncertain.

An epilogue completes the book, in which Ruddiman presents his own views on the issues of climate change. He decries the habit in the press of wanting "clever, crisply phrased sound bites" and he laments the polarization regarding global warming. He calls for recognition of the underlying reality that ${ }^{\alpha} \mathrm{draconian}$ economic sacrifices" will be needed, and that this should put the global-warming debate "in a dearer perspective". So ends an excellent book summarizing and placing in context the age-old influence of humans on atmospheric composition, dimate and global warming.

However, just as it is difficult to prove that Earth's warming over the industrial period has been caused by the emission of greenhouse gases through human activities, it is also difficult to prove that Stone Age farming caused a lack of cooling thousands of years ago. The debates about the causality of both present-day warming and the warming needed in the past to delay an ice age can be summarized briefly in terms of the concept of climate forcing, the imposed change in energy balance. For causality of global warming to be demonstrated, three interconnected premises must hold: the anthropogenic global forcing must be positive and substantial in magnitude; the temperature change must be positive and beyond the range of natural variability; and the former must be the cause of the latter.

If Ruddiman used the concept of forcing to strengthen and refine his thesis, he could address more specifically the uncertainties in assigning the causality of temperature increases to Stone Age agronomists. He could find further reasons for the higher sensitivity of temperature to early changes in methane and carbon dioxide levels. He would have to consider smoke from biomass burning as a 